Vietnam Journal of Earth Sciences, 38(2), 153-165, DOI: 10.15625/0866-7187/38/2/8598

Vietnam Academy of Science and Technology
(VAST) Vietnam Journal of Earth Sciences
http://www.vjs.ac.vn/index.php/jse

\title{
Continuous GPS network in Vietnam and results of study on the total electron content in the South East Asian region
}

Le Huy Minh*1, Tran Thi Lan¹, C. Amory-Mazaudier2, R. Fleury33, A. Bourdillon4, J. Hu, Vu Tuan Hung5, Nguyen Chien Thang', Le Truong Thanh1, Nguyen Ha Thanh ${ }^{1}$

${ }^{1}$ Institute of Geophysics, VAST

${ }^{2}$ LPP/UPMC/Polytechnique/CNRS, UMR 7648, France

${ }^{3}$ Lab-STICC UMR 6285 Mines-Télécom Télécom Bretagne, France

${ }^{4}$ Institut d'Electronique et de Télécommunication, Université de Rennes, France

${ }^{5}$ National Taiwan University, Republic of China

Received 19 January 2016. Accepted 27 April 2016

ABSTRACT

This study presents the continuous GPS network in Vietnam and the results of study on time variations of the total electron content (TEC) in the South East Asian equatorial ionization anomaly (EIA) for the 2006-2013 period. In each year we observe a semiannual pattern of amplitude of the EIA crests with its maximum amplitude at equinox. In both hemispheres, the amplitude of the crest is larger in northern spring equinox than in autumn from 2006 to 2008 (descending phase of solar cycle) and smaller in spring than in autumn from 2009 to 2011 (increasing phase of solar cycle), from 2012-2013 (maximum period of solar cycle) the amplitudes of the crests in spring and autumn are equivalent. We also observe an asymmetry between the amplitude and the position of the two crests of ionization. There is a very high level of correlation between the amplitude of the TEC at the two crests and the sunspot number is approximately equal to 0.9 . During the deep solar minimum 2008-2009, the amplitude of crests of ionization becomes small during several months in summer and winter (about $20 \mathrm{TECu}$ ). The results show that both crests move more significantly equatorward in winter than in other seasons and there is a tendency for both crests to appear earlier in winter and later in summer. In the solar minimum years, the amplitudes of the crests are minimal; the positions of the crests are nearer the magnetic equator and the crests appear earlier than in other years.

Keywords: Equatorial ionization anomaly; Total electron content (TEC); GPS technology; Sunspot; Solar cycle.

(C)2016 Vietnam Academy of Science and Technology

\section{Introduction}

Within the framework of the cooperation between Institute of Geophysics-VAST, Universities of Rennes 1 and Telecom Bretagne (Amory et al., 2006), two GPS receivers were installed in Hanoi (HAN1, PHUT) and in Hoc Mon (Ho Chi Minh City, HOCM) from May

*Corresponding author, Email: 1hminhigp@gmail.com
2005; and another was installed in Hue (HUES) from January 2006. This is the first time these continuously operating GPS receivers have been setup in Vietnam for monitoring the total electron content (TEC) and ionospheric scintillation. Within the framework of Institute of Geophysics-VAST and National Taiwan University, six continuously operating GPS receivers were installed in the Northwest of Vietnam from 
Le Huy Minh, et al./Vietnam Journal of Earth Sciences 38 (2016)

November 2009. From September 2011, another GPS receiver was setup in Vinh, whose continuous operation has been sustained so far. Within the framework of the national independent project "Study and assessment of earthquake and tsunami hazards in Ninh Thuan and the surrounding region for the site selection of nuclear power plant" and the project "Study on the impact of seismotectonic activity on the stability of Song Tranh 2 hydro power plant in Bac Tra My, Quang Nam province", the continuous GPS measurement was carried out at 06 locations in Central Vietnam during 1-2 years. Thus, from 2005 uptonow, Institute of Geophysics has created the continuous GPS network at 18 locations to provide the important database for the research on the ionosphere, water vapor content in the troposphere and tectonic movement of Earth's crust in Vietnam and adjacent region.The use of GPS technology to examine the ionosphere and the troposphere was mentioned in some previous studies (Le Huy Minh et al., 2006; 2010; Duong Chi Cong, 2010). This article presents the results of utilizing the continuous GPS data in Vietnam and adjacent region to study the characteristics of equatorial ionization anomaly (Breit and Tube, 1926; Namba and Maeda, 1939; Appleton, 1946) in the South East Asian region between 2006 and 2013. It should be noted that although many studies on TEC in Asia have been conducted (Walker et al., 1994; Tsai et al., 2001; Chen et al., 2008; Zhao et al., 2009); however, there are no studies dealing with the subequatorial network in Vietnam as well as no results for a long-time series, about one solar cycle of 11 years has been reported uptonow.

\section{Data and calculation method}

Data of the continuous GPS stations in Vietnam and the stations of International GNSS Services (IGS): KUNM (China), CUSV (Thailand), NTUS (Singapore), BAKO (Indonesia) used in this study are listed in Table 1 and the distribution of stations are illustrated in Figure 1. To have relatively complete information about the anomaly crest in the southern hemisphere in months when the stations NTUS or BAKO provide no data, we use data from the stations SAMP, MNKL and XMIS instead. The position of the magnetic equator in the latitude of $7-8^{\circ} \mathrm{N}$ is also presented in Figure 1.

We use the pseudorange measurements between the GPS receivers and satellites to calculate the total electron content along the transmission line according to the formula (Klobuchar, 1986; Liu et al., 1996):

$$
\text { TEC }=\frac{1}{40.3}\left(\frac{f_{1}^{2} f_{2}^{2}}{f_{1}^{2}-f_{2}^{2}}\right)\left(p_{2 j}^{i}-p_{1 j}^{i}-\left(b^{i}+b_{j}\right)\right) \operatorname{TECu}(1)
$$

where $f_{1}=1575.42 \mathrm{MHz}$ and $f_{2}=1227.60$ $\mathrm{MHz}$ are the GPS frequencies, $p_{1 j}^{i}$ and $p_{2 j}^{i}$ are the pseudorange measurements from the satellite $\mathrm{i}$ to the receiver $\mathrm{j}$ corresponding to the frequencies $f_{1}$ and $f_{2}, \mathrm{~b}$ is the instrumental bias of satellite $i, b^{i}$, or of receiver $j, b_{j}, T E C u$ is the unit of total electron content, 1 $\mathrm{TECu}=10^{16} \mathrm{el} / \mathrm{m}^{2}$. The vertical total electron content, VTEC, observed at the pierce point of the ionosphere is determined from the single-layer model (Klobuchar, 1986):

$$
V T E C=T E C \cdot \cos \left[\arcsin \left(\frac{R \cos \theta}{R+h}\right)\right]
$$

where $\theta$ is the satellite elevation angle, $\mathrm{R}=6371.2 \mathrm{~km}$ is the average radius of the Earth, and $\mathrm{h}$ is the height of the ionosphere above ground level, often considered as $\mathrm{h}=400 \mathrm{~km}$ (Zhao et al., 2009).

To calculate TEC from (1) and VTEC from (2), we must know the instrumental biases of satellite $b^{i}$ and of receiver $b_{j}$. Many organizations responsible for treatments of the rinex data of the International GNSS Service (IGS) provide the daily value of satellite bias, known as Differential Code Bias (DCB). The receiver bias $b_{j}$ is a true value; based on the method of Komjathy et al. (2005) we use the global ionosphere model to estimate the receiver bias at certain location. In reality, it is unnecessary to know the receiver and satellite 
Vietnam Journal of Earth Sciences, 38(2), 153-165

biases separately; we can estimate the sum $b_{j}^{i}=b^{i}+b_{j}$ by comparing VTEC value calculated in the formulas (1) and (2) based on the assumption that $b^{i}+b_{j}=0$ and the VTEC value calculated in the global TEC model CODG, which can be retrieved from the website $\mathrm{ftp} / /$ cddis.gsfc.nasa.gov/gps/products/ionex. For each station, each day $t$, and each satellite, $b_{j}^{i}$ is evaluated at every observation time $t_{k}$, $b_{j}^{i}\left(t_{k}\right)$, and then the value $b_{j}^{i}(t)$ of each day is chosen as the median of values $b_{j}^{i}\left(t_{k}\right)$. The calculation usually was carried out for onemonth data, so the value $b_{j}^{i}$ of the month is taken as the median of daily values $b_{j}^{i}(t)$. Figure 2 represents the root mean square value of instrumental biases $b_{j}^{i}$ (RMS_b) for each satellite PRN compared to the monthly median value for the receiver in station PHUT in March 2011. It can be seen that the root mean square values range between 1 and 7.2 $\mathrm{TECu}$ depending on the satellite. Among 31 satellites operating in that month, 22 satellites have RMS b $<5 \mathrm{TECu}$, and 9 satellites have RMS_b $>5$ TECu. From Figure 2, it can be indicated that the root mean square values for all satellites are in the range of 4-5 TECu; therefore, the error of TEC mapping is about 4-5 TECu. It should be noted that the global TEC model is estimated during a period of 1-2 hours. The method used in this study provides the value of TEC at every observation time of 30 s, hence it is possible to see the finer structures of TEC that are smoothed by the global model CODG.

Table 1. Continuous GPS stations and their coordinates, the data of which are used in the study

\begin{tabular}{|c|c|c|c|c|c|c|}
\hline \multirow{2}{*}{ No. } & \multirow{2}{*}{ Station } & \multicolumn{2}{|c|}{ Geographic coordinates } & \multirow{2}{*}{ Magnetic latitude (2010) } & \multirow{2}{*}{ Instrument } & \multirow{2}{*}{ Period of time } \\
\hline & & Longitude & Latitude & & & \\
\hline 1 & MTEV & 102.80719 & 22.38791 & 15.92 & NETRS & 12/2009-present \\
\hline 2 & MLAY & 103.15385 & 22.04187 & 15.54 & NETRS & 1/2012-present \\
\hline 3 & DBIV & 103.01829 & 21.38992 & 14.84 & NETRS & 11/2009-present \\
\hline 4 & TGIV & 103.41804 & 21.59225 & 15.06 & NETRS & 11/2009-present \\
\hline 5 & SMAV & 103.74971 & 21.05629 & 14.49 & NETRS & 6/2010-present \\
\hline 6 & SLAV & 103.90664 & 21.32529 & 14.78 & NETRS & 12/2009-present \\
\hline 7 & MOCV & 104.63545 & 20.84406 & 14.26 & NETRS & $6 / 2010-6 / 2011$ \\
\hline 8 & HAN1 & 105.79973 & 21.04740 & 14.51 & GSV4004 & $5 / 2005-2 / 2009$ \\
\hline 9 & PHUT & 105.95872 & 21.02938 & 14.49 & GSV4004 & 2/2009-present \\
\hline 10 & VINH & 105.69659 & 18.64999 & 11.91 & CORS5700 & 9/2011-present \\
\hline 11 & HUES & 107.59265 & 16.45919 & 9.58 & GSV4004 & 1/2006-present \\
\hline 12 & HOCM & 106.55979 & 10.84857 & 3.47 & GSV4004 & $5 / 2005-10 / 2012$ \\
\hline 13 & PHOD & 108.96842 & 11.45501 & 4.21 & CORS5700 & $8 / 2012-12 / 2013$ \\
\hline 14 & PHUO & 108.93735 & 11.70926 & 4.49 & CORS5700 & $8 / 2012-12 / 2013$ \\
\hline 15 & PHUQ & 108.93334 & 10.51638 & 3.20 & CORS5700 & $12 / 2012-12 / 2013$ \\
\hline 16 & TAMB & 108.20444 & 11.62165 & 4.37 & CORS5700 & $8 / 2012-12 / 2013$ \\
\hline 17 & HSON & 108.18322 & 11.10855 & 3.82 & CORS5700 & $8 / 2012-12 / 2013$ \\
\hline 18 & TNGO & 108.20385 & 15.44722 & 8.50 & CORS5700 & 4/2014-present \\
\hline 19 & KUNM & 102.79720 & 25.02954 & 18.79 & IGS station & $1 / 2006-1 / 2013$ \\
\hline 20 & CUSV & 100.53392 & 13.73591 & 6.43 & IGS station & 5/2008-present \\
\hline 21 & NTUS & 103.67996 & 1.34580 & -7.05 & IGS station & 1/2006-present \\
\hline 22 & BAKO & 106.84891 & -6.49106 & -15.52 & IGS station & 1/2006-present \\
\hline 23 & SAMP & 98.71472 & 3.62161 & -4.76 & IGS station & \\
\hline 24 & MNKL & 102.27021 & -5.36365 & -14.52 & IGS station & \\
\hline 25 & XMIS & 105.68350 & -10.44996 & -19.99 & IGS station & \\
\hline
\end{tabular}


Le Huy Minh, et al./Vietnam Journal of Earth Sciences 38 (2016)

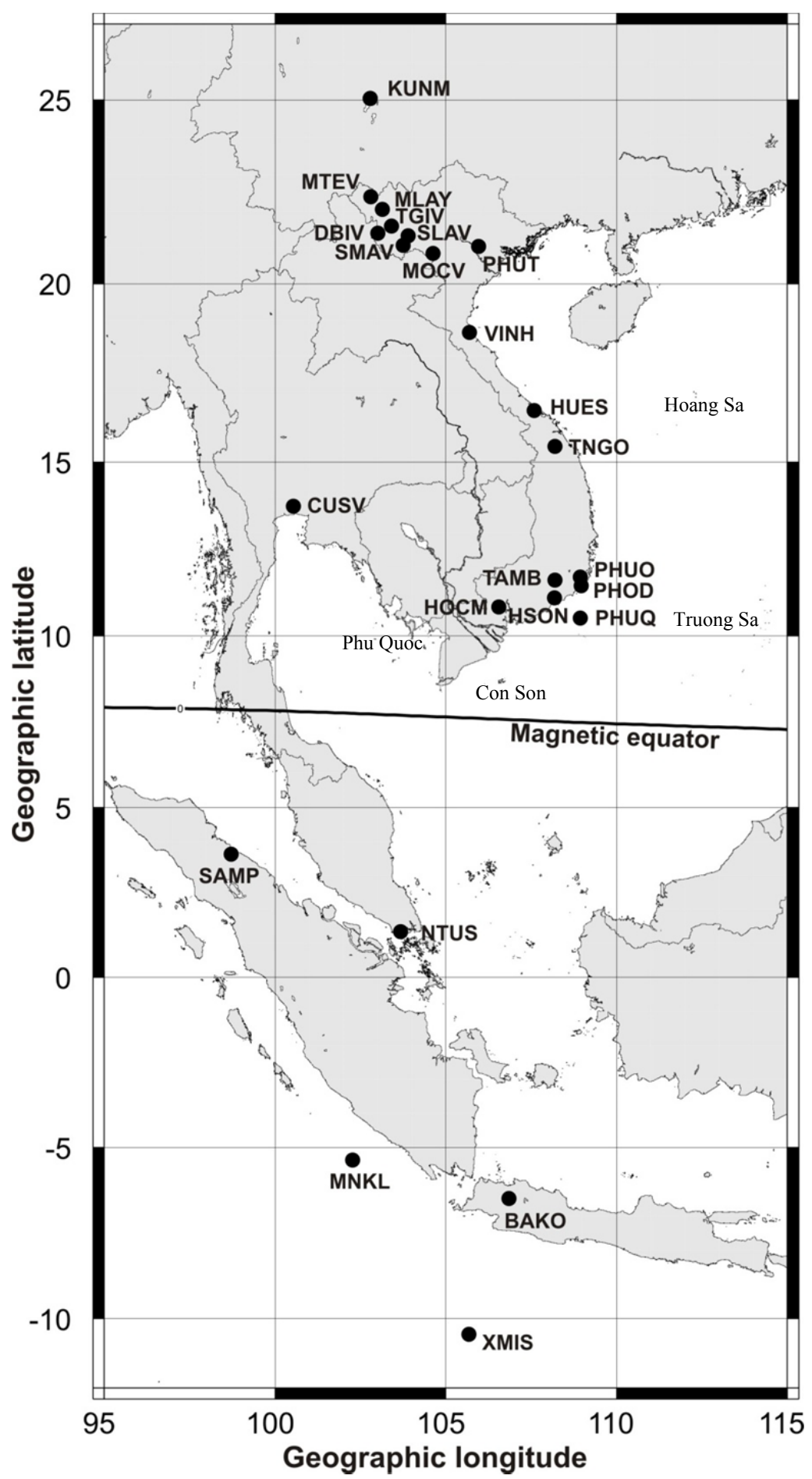

Figure 1. Location of the GPS stations, the data of which are used in the study 
Vietnam Journal of Earth Sciences, 38(2), 153-165

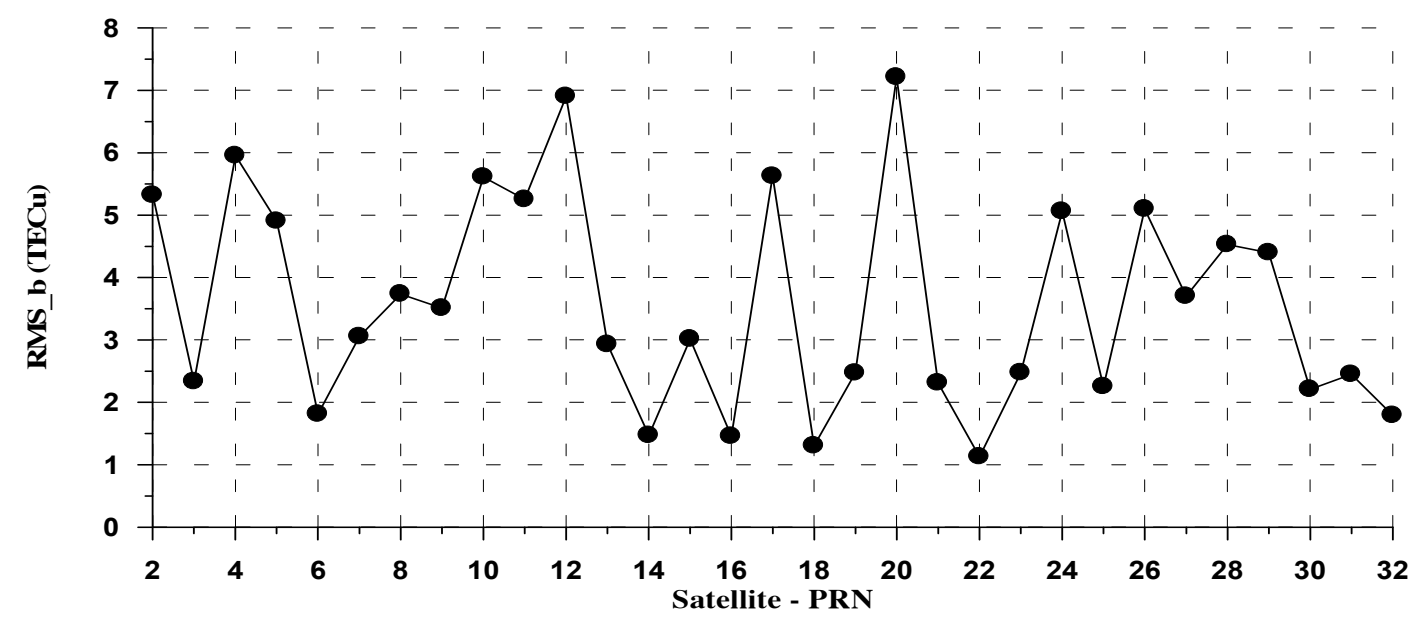

Figure 2. Root mean square RMS_b of instrumental bias in each pair of satellite PRN and GPS receiver in Phu Thuy in March 2011

\section{Results and discussion}

The method of establishing the temporallatitudinal TEC maps has been introduced in previous articles (L. H. Minh et al., 2006; Le Huy et al., 2014) as well as in international publications (Huang et al., 1989; Liu et al., 1996; Tsai et al., 2001). In this article, we present the result of establishing the temporallatitudinal average monthly TEC maps in the period of 2006-2013. Figures $3 a$ and $3 b$ illustrate the monthly average TEC maps for 12 months in 2009 and 2013, respectively; The maps in Figures $3 a$ and $3 b$ are drawn in the same color scale to facilitate the comparison. The structural morphology of equatorial ionization anomaly is clearly shown with a depression at about $8^{\circ} \mathrm{N}$, i.e. at the magnetic equator; two maximum crests are at two sides of the magnetic equator; the northern crest is observed near the latitude of $20 \div 22^{\circ} \mathrm{N}$, i.e. in the North of our country's territory; and the southern crest is observed in the latitude of $5-7^{\circ} \mathrm{S}$. Each year, the amplitude of crest of TEC reaches a maximum at the spring equinox (MarchApril) and the autumn equinox (SeptemberOctober) or perhaps within October-
November. The amplitude of crest of TEC in 2013 is greater than that in 2009.

The crest of equatorial ionization anomaly can be characterized by latitude $\mathrm{L}_{\mathrm{c}}$, occurrence time $T_{c}$ and amplitude $I_{c}$ with affixes $N$ or $\mathrm{S}$ added to distinguish the anomaly crest in the northern hemisphere from that in the southern hemisphere. We examined temporal variations of parameters of crests $\left(\mathrm{L}_{\mathrm{c}}^{\mathrm{N}, \mathrm{S}}, \mathrm{T}_{\mathrm{c}}^{\mathrm{N}, \mathrm{S}}, \mathrm{I}_{\mathrm{c}}^{\mathrm{N}, \mathrm{S}}\right)$ as considered by Huang et al., 1989; Walker et al., 1994; Huang \& Cheng, 1996; Tsai et al., 2001; Wu et al., 2004, 2008; Zhao et al., 2009; Le Huy et al., 2014. Figure 4 presents the average monthly number of sunspot and the monthly average amplitude of ionization anomaly crests from 2006 to 2013. In the graph of sunspot number SSN, discrete points are monthly average values, the solid line is moving average values of 13 months. In curves representing the change of $I_{c}^{N, S}$, dots and relevant connecting lines are monthly average values, bold lines in the middle are also moving average values of 13 months. The calculation of moving average values are made by using the moving average smooth command in Matlab, the result shows that the first and last values in the output data series are the same as those in the input one. It 
Le Huy Minh, et al./Vietnam Journal of Earth Sciences 38 (2016)

is inappropriate and therefore, the values in extremities should be excluded. It means that values of amplitude of crest are moving- averaged in 13 months, but those in January 2006 and December 2013 are not taken after calculating the moving average.
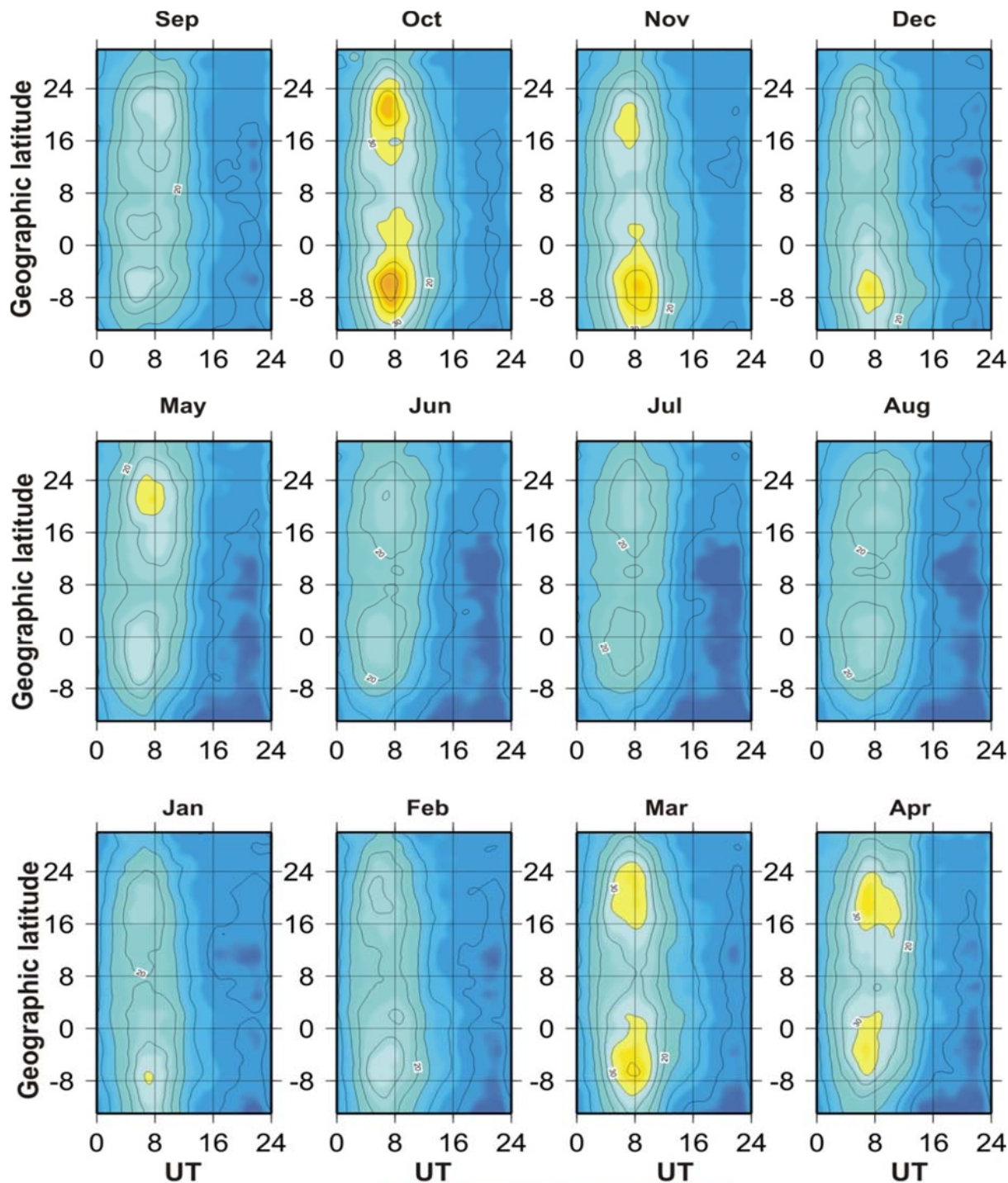

Feb
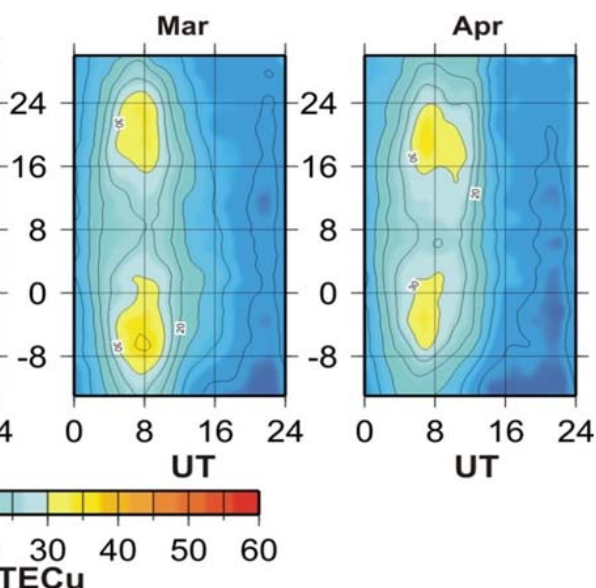

Figure 3. a) The temporal-latitudinal monthly average TEC maps in 2009. Contour interval: 5TECu; 
Vietnam Journal of Earth Sciences, 38(2), 153-165
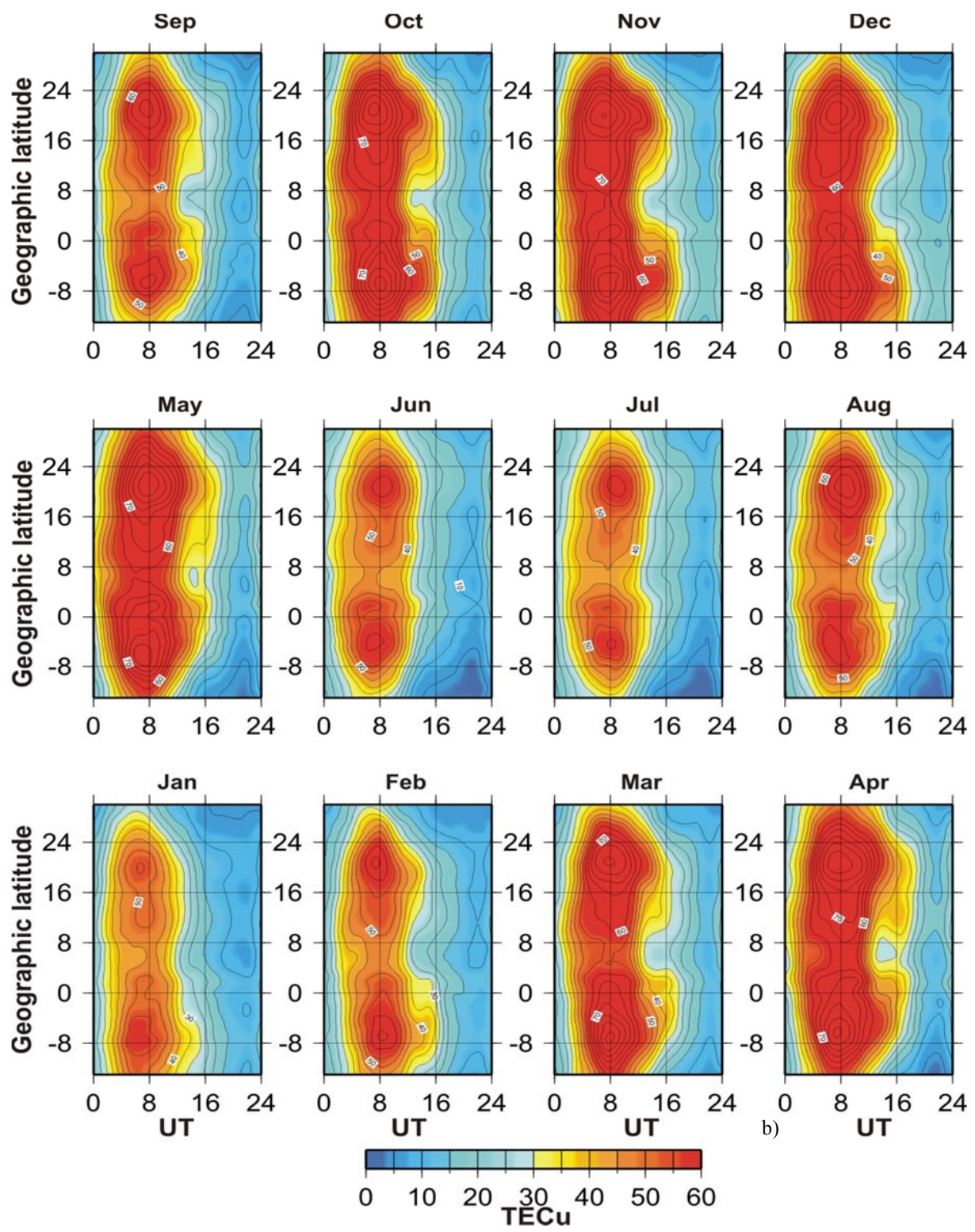

Figure 3b. The temporal-latitudinal monthly average TEC maps in 2013.s Contour interval: 5TECu

Figure 4 shows that in the deep solar minimum of the 2008-2009 period, the amplitude of anomaly crest is very small, only about 20 $\mathrm{TECu}$, especially at the summer solstice in the northern hemisphere (June or July). At the winter solstice in the northern hemisphere (December), $I_{c}^{S}$ is often larger than $I_{c}^{N}$, at the summer solstice (July) $I_{c}^{N}$ is often larger than $I_{c}^{S}$. During these years, the amplitude $I_{c}^{N, S}$ in December (winter in the northern hemisphere) is always larger than that in July (winter in the southern hemisphere). It signifies that the winter anomaly (Rishbeth \& Muller-Wodarg, 2006) only occurs in the northern hemisphere, 
Le Huy Minh, et al./Vietnam Journal of Earth Sciences 38 (2016)

but not in the southern hemisphere; this is an important hemispheric asymmetry of equatorial ionization anomaly. From 2006 to 2008, during the descending phase of the solar cycle, $I_{c}^{N, S}$ at the spring equinox is larger than at the autumn equinox. From 2009 to 2011, during the increasing phase of the solar cycle, the maximum amplitude at the autumn equinox is larger than at the spring equinox. During 2012 and 2013, maximum period of the solar cycle without a clear weakening trend, the maximum amplitudes at spring and autumn equinoxes are equivalent. The asymmetry of TEC in the equatorial ionization anomaly was mentioned by some international authors (Tsai et al., 2001; Wu et al., 2004, 2008; Rama Rao et al., 2006; Chakraborty \&
Hajra, 2008; Mala et al., 2009; Zhao et al., 2009). Correlation coefficients between the monthly average number of sunspot and the monthly average amplitude of anomaly crest are 0.909 and 0.897 in the northern and southern crests, respectively. These coefficients show better correlation than the correlation between the critical frequency of $\mathrm{F}_{2}$ layer in Phu Thuy and the sunspot number, which is equal to $\sim 0.84$ (Pham Thi Thu H. et al., 2011). The correlation coefficients of moving average values of 13 months are 0.995 and 0.994 in the northern and southern crests, respectively. Thus, the change in monthly average amplitude of equatorial ionization anomaly has a high correlation with the sunspot number.
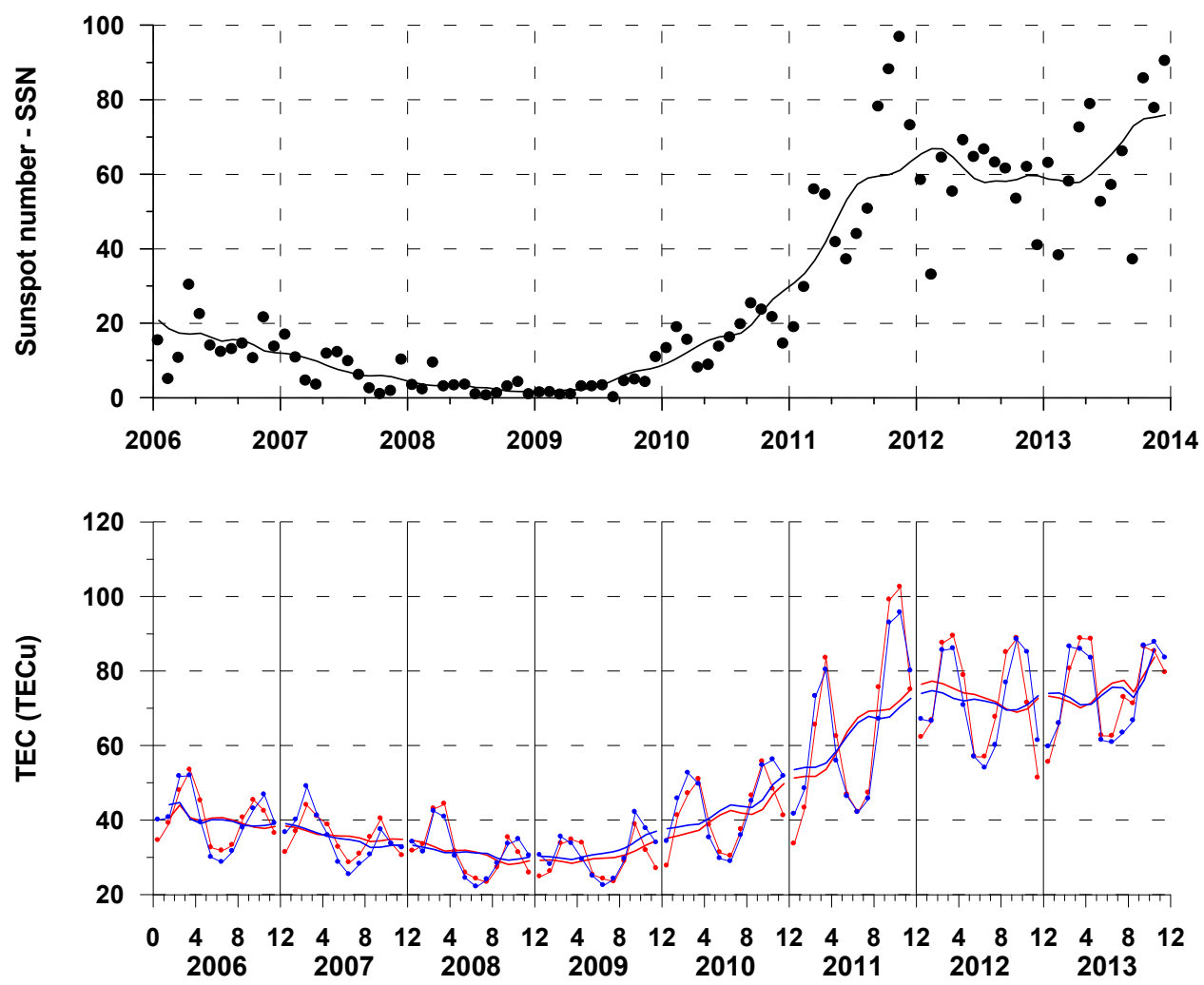

Figure 4. The monthly mean sunspot number (top) and the amplitudes of equatorial ionization anomaly crests (bottom). Red dots and red lines - for northern crest, blue dots and blue lines for southern crest 
Vietnam Journal of Earth Sciences, 38(2), 153-165

For further detail consideration of seasonal variations of anomaly crests, we use monthly average values of amplitude $I_{c}^{N, S}$ minus moving average values $I_{c, 13}^{N, S}\left(\right.$ DeltaI $=I_{c}^{N, S}$ $\left.I_{c, 13}^{N, S}\right)$. The results shown in Figure 5 represent that the asymmetry between the spring and autumn equinoxes markedly decreases, the difference between amplitudes of crest at the spring and autumn equinoxes is not large as in Figure 4; however, anomaly amplitude in December in most of these years (except 2011) is larger than that in July. It means that the winter anomaly in the northern hemisphere often occurs.
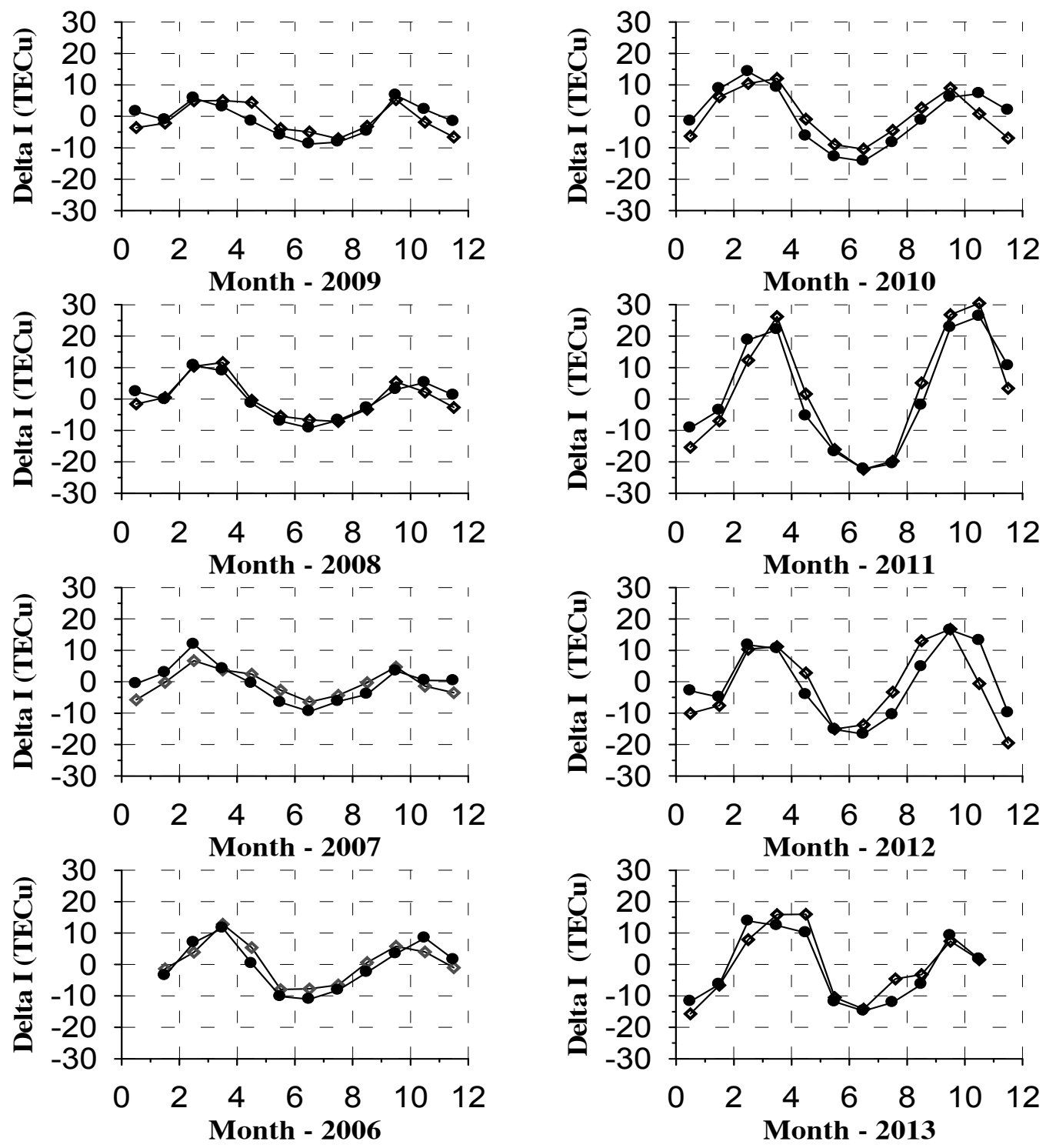

Figure 5. Seasonal variations of monthly mean EIA crests, rhombic dots for northern crest, round dots for southern crest 
Le Huy Minh, et al./Vietnam Journal of Earth Sciences 38 (2016)

Figure 6 represents the latitude and occurrence time of the crests in both hemispheres. Spring, summer, autumn, and winter months in two hemispheres are also presented in Figure 6 to facilitate the analysis of seasonal effect. Figure 6 shows that during the studied period, the southern crest move poleward more significantly in summer than in other seasons. The northern crest also follow this trend, but less obviously. This observation is in accordance with observations of Zhao et al. (2009). The graph on the right of Figure 6 expresses a tendency for both crests to appear earlier in winter and later in summer. Figure 7 represents the

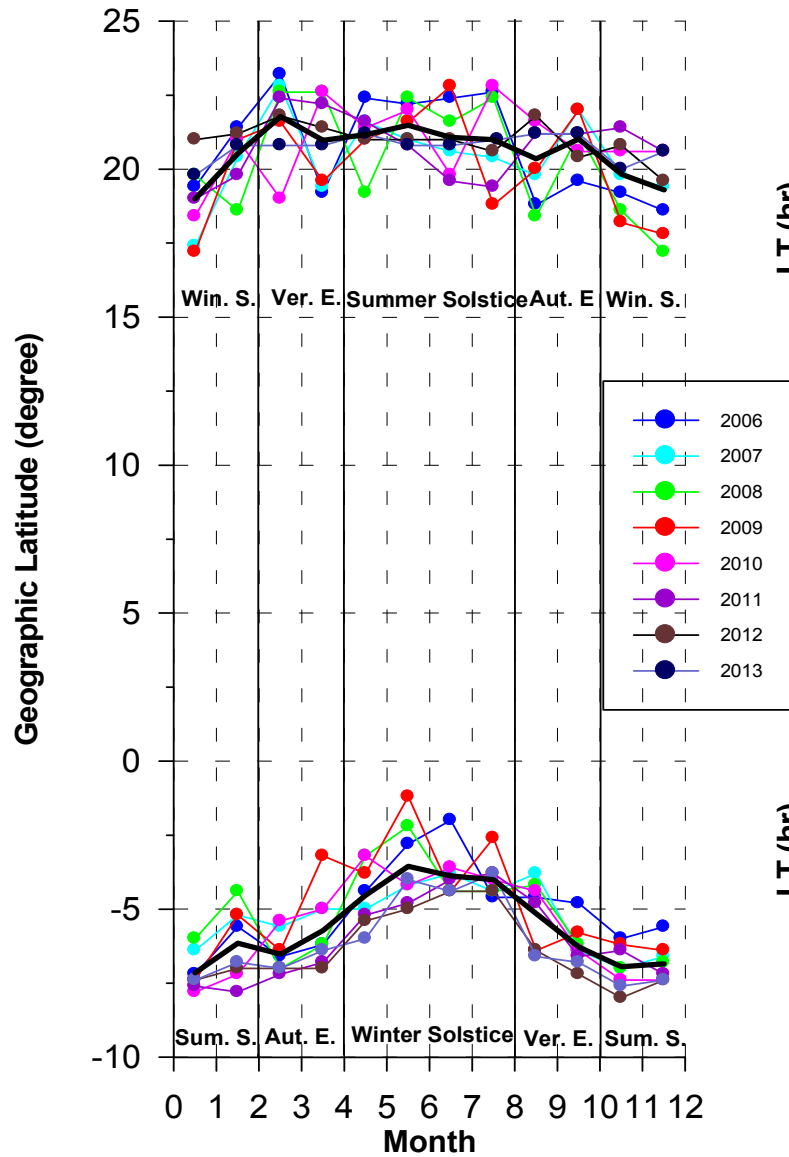

difference between occurrence times $(\Delta t)$ of anomaly crests in the northern and southern hemispheres in the period of 2006-2013. There is a tendency for the northern crest to appear earlier than the southern crest in January, February, November and December (winter months in the northern hemisphere), thus $\Delta t<0$, whereas in May, June, July and August (summer months in the northern hemisphere), the northern crest appears later than the southern crest and $\Delta \mathrm{t}>0$. This can be explained by the thermospheric general circulation model (Torr \& Torr, 1973; Mayr et al., 1977), which is the circulation between solstices with two transitions at equinoxes.

Figure 6. Latitude (on the left) and occurrence time (on the right) of equatorial ionization anomaly crests from 2006 to 2013. Bold solid lines: corresponding average values for 2006-2013 period 
Vietnam Journal of Earth Sciences, 38(2), 153-165

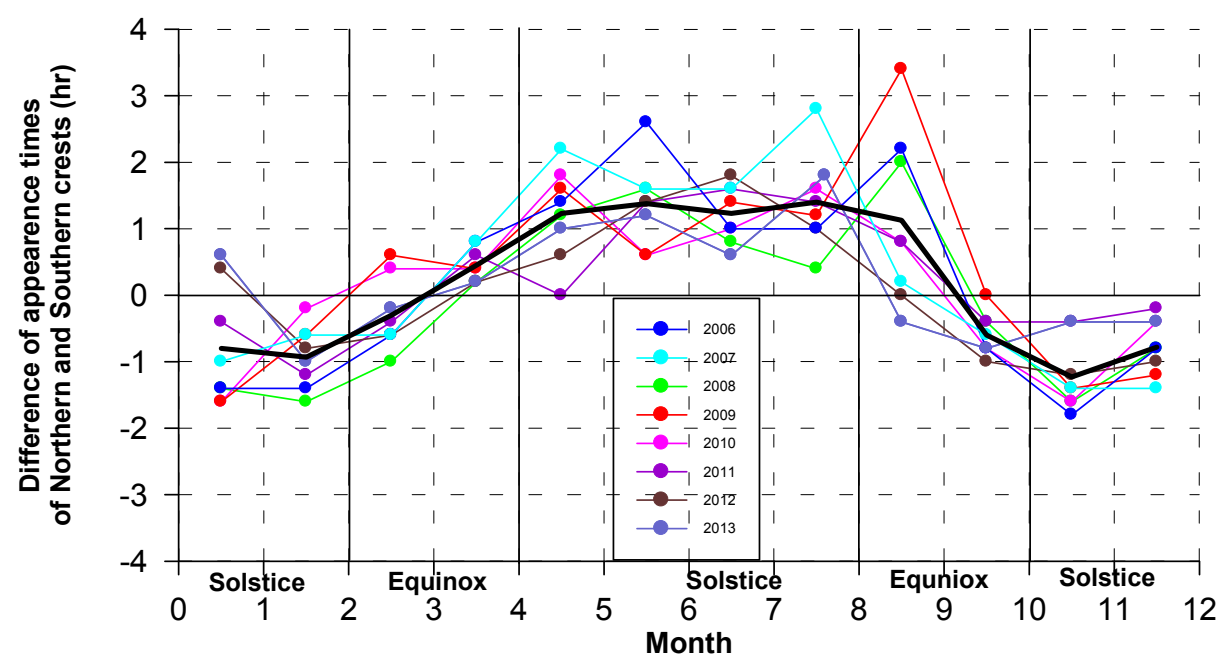

Figure 7. Difference between the occurrence times of the northern and southern monthly anomaly crests for every year during 2006-2013 period. Bold solid lines: corresponding average values for 2006-2013 period

To investigate annual variations of characteristics of anomaly crest, annual mean values of parameters of the crests are calculated in the studied period and presented in Figure 8. As can be seen in Figure 4, in the studied period, 2008-2009 is the deep solar minimum; in Figure 8 , in 2009 anomaly crests are nearest to the magnetic equator, amplitudes of both crests have the smallest values, the earliest occurrence time in the southern crest is in 2009 , and that in the northern crest is in 2008. In case of increasing solar activity, the crests move further from the equator, the amplitude of crest increases and the occurrence time is later.
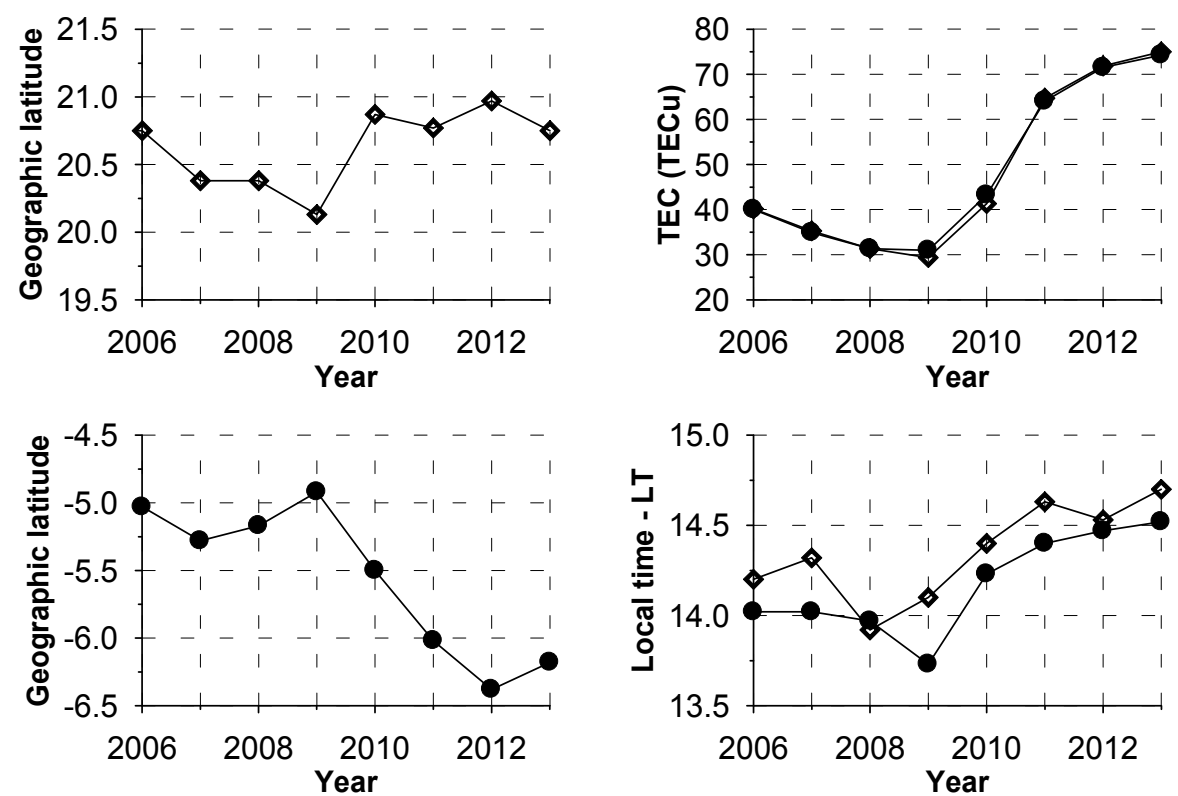

Figure 8. The annual average latitudes, occurrence times and amplitudes of EIA crests in 2006-2013 period. Rhombic dots for northern crest, round dots for southern crest 
Le Huy Minh, et al./Vietnam Journal of Earth Sciences 38 (2016)

\section{Conclusions}

This study presents variations of monthly mean total electron content in the crest of South East Asian equatorial ionization anomaly by using data of the continuous GPS network along the meridian of $105^{\circ} \mathrm{E}$ in both hemispheres. The TEC calculation using pseudoranges observed in GPS stations is represented. We can draw some conclusions as follows:

We observed the semiannual pattern of amplitude of the EIA crests. In both hemispheres, the amplitude of crest is larger at the northern spring equinox than at the autumn equinox from 2006 to 2008, and smaller at the spring equinox than at the autumn equinox from 2009 to 2011. In the maximum period of solar cycle 2012-2013, the amplitudes of crests at two equinoxes are equivalent.

There is a high correlation between TEC amplitudes in two crests and the sunspot number, with the correlation coefficient of $\sim 0.9$.

In the deep solar minimum years 20082009 , amplitudes of anomaly crests become small, about $20 \mathrm{TECu}$ in the summer and winter months.

The crests tend to move equatorward more significantly in winter than in other seasons, and there is a tendency for both crests to appear earlier in winter and later in summer.

In the deep solar minimum, the annual mean latitudes of anomaly crests are nearer the equator, the annual mean TEC amplitudes of crests are minimal and the occurrence time is earlier than in other years.

\section{Acknowledgements}

This study has been completed with the financial support from the project of Vietnam Academy of Science and Technology VAST01.02/15-16.

\section{References}

Amory-Mazaudier C., Le Huy M., Y. Cohen, V. Doumbia, A. Bourdillon, R. Fleury, B. Fontaine, Ha Duyen C., A.
Kobea, P. Laroche, P. Lassudrie-Duchesne, Le Viet H., Le Truong T., Luu Viet H., M. Menvielle, Nguyen Chien T., Nguyen Xuan A., F. Ouattara, M. Petitdidier, Pham Thi Thu H., Pham Xuan T., P. Philippon, Tran Thi L., Vu Thien H., and P. Vila, 2006. Sun-Earth System Interaction studies over Vietnam: an international cooperative project, Ann. Geophys., 24, 3313-3327.

Appleton E., 1946. Two anomalies in the Ionosphere, Nature, $157,691$.

Breit G. and M. A. Tuve, 1926. A test of the existence of the conducting layer, Phys. Rev., 28, 554-575.

Chakraborty S. K., and R. Hajra, 2008. Solar control of ambient ionization of the ionosphere near the crest of the equatorial anomaly in the Indian zone, Ann. Geophys., 26, 47-57.

Chen C.H., J.Y. Liu, K.Yumoto, C.H. Lin and T.W. Fang, 2008. Equatorial ionization anomaly of the total electron content and equatorial electrojet of ground-based geomagnetic field strength, J. Atmos. Solar Terr. Phys., 70, 2172-2183.

Duong Chi Cong, 2010. Study on scientific basis and reality of utilizing GPS technology to examine the condition of the ionosphere and the troposphere. Project of Ministry of Natural Resources and Environment. Vietnam Institute of Geodesy and Cartography. http://www.vigac.vn (in Vietnamese).

Huang Y.-N. and K. Cheng, 1996. Solar cycle variations of the equatorial ionospheric anomaly in total electron content in the Asian region, J. Geophys. Res., 101, A11, 24, 513-520.

Huang Y.-N., K. Cheng, and S.-W Chen, 1989. On the equatorial anomaly of the ionosphere total electron content near the northern anomaly crest region, J. Geophys. Res., 94, A10, 13, 515-525.

Klobuchar J., 1986. Design and characteristics of the GPS ionospheric time-delay algorithm for single frequency users, in Proceedings of PLANS'86 - Position Location and Navigation Symposium, Las Vegas, Nevada, 280-286, 4-7 November, 1986.

Komjathy A., L. Sparks, B. D. Wilson, and A. J. Mannucci, 2005. Automated daily processing of more than 1000 ground-based GPS receivers for studying intense ionospheric storms, Radio Science, VOL. 40, RS6006, doi:10.1029/2005RS003279.

Le Huy M., C. Amory-Mazaudier,R. Fleury, A. Bourdillon, P. Lassudrie-Duchesne, L. Tran Thi, T. Nguyen Chien and T. Nguyen Ha, P. Vila, 2014. Time variations of the total electron content in the Southeast Asian equatorial 


\section{Vietnam Journal of Earth Sciences, 38(2), 153-165}

ionization anomaly for the period 2006-2011, Advances in Space Research, 54, 355-368, http://dx.doi.org/10.1016/j.asr.2013.08.03.

Le Huy Minh, A. Bourdillon, P. Lasudrie-Duchesne, R. Fleury, Nguyen Chien Thang, Tran Thi Lan, Ngo Van Quan, Le Truong Thanh, Hoang Thai Lan, Tran Ngoc Nam, 2006. Determination of the ionospheric total electron content in Vietnam through data of GPS stations, Journal of Geology, A269, 54-62 (in Vietnamese).

Le Huy Minh, Pham Xuan Thanh, Tran Thi Lan, Nguyen Chien Thang, Nguyen Ha Thanh, Le Truong Thanh, 2010. GPS technology and its application in study on Earth science, Proceedings of Scientific Works on the $35^{\text {th }}$ Anniversary of Vietnam Academy of Science and Technology, Subcommittee: Earth Science, 65-79, ISBN 978-604-913016-8 (in Vietnamese).

Liu J. Y., H. F. Tsai, and T. K. Jung, 1996. Total electron content obtained using the global positioning system, TAO, 7/1, 107-117.

Mala S. B., H. P. Joshi, K. N. Iyer, M. Aggarwal, S. Ravindran, and B. M. Pathan, 2009. TEC variations during low solar activity period (2005-2007) near the Equatorial Ionospheric Anomaly Crest region in India, Ann. Geophys., 27, 1047-1057.

Mayr H. G., I. Harris, and N. W. Spencer, 1978. Some properties of upper atmosphere dynamics, Rev. Geophys. Space Physics, V16, 539-565.

Namba S., and K.-I. Maeda, 1939. Radio wave propagation, 86pp, Corona Publishing, Tokyo.

Pham Thi Thu H., C. Amory-Mazaudier, and Le Huy M., 2011. Time variations of the ionosphere at the northern tropical crest of ionization at Phu Thuy, Vietnam, Ann. Geophys., 29, 197-207.
Rama Rao P. V. S., S. Gopy Krishna, K. Niranjan, and D. S. V. V. D. Prasad, 2006. Temporal and spacial variations in TEC using simultaneous measurements from the Indian GPS network of receivers during the low solar activity period of 2004-2005, Ann. Geophys., 24, 3279-3292.

Rishbeth H. and I. C. F. Muller-Wodarg, 2006. Why is there more ionosphere in January than in July? The annual asymmetry in the F2-layer, Ann. Geophys., 24, 3293-3311.

Torr M. R. and D. G. Torr, 1973. The seasonal behavior of the F2-layer of the ionosphere, J. Atmos. Terr. Phys., 35, 2237-2251.

Tsai, H.-F., J.-Y. Liu, W.-H. Tsai and C.-H. Liu, 2001. Seasonal variations of the ionospheric total electron content in Asian equatorial anomaly regions, J. Geophys. Res., 106, No. A12, 30, 363-369.

Walker G. O., J. H. K. Ma, and E. Golton, 1994. The equatorial ionospheric anomaly in electron content from solar minimum to solar maximum for South East Asia, Ann. Geophys., 12, 195-209.

Wu C. C., C. D. Fry, J. Y. Liu, K. Liou and C. L. Tseng, 2004. Annual TEC variation in the equatorial anomaly region during the solar minimum: September 1996-August 1997, J. Atmos. Sol. Terr. Phys., 66, 199-207.

Wu C. C., K. Liou, S. J. Shan, and C. L. Tseng, 2008. Variation of ionospheric total electron content in Taiwan region of the equatorial anomaly from 1994-2003, Adv. Space Res., 41, 611-616.

Zhao B., W. Wan, L. Liu, Z. Ren, 2009. Characteristices of the ionospheric total electron content of the equatorial ionization anomaly in the Asian-Australian region during 1996-2004, Ann. Geophys., 27, 3861-3873. 